\title{
Patterned growth of single-walled carbon nanotube arrays from a vapor-deposited Fe catalyst
}

\section{Citation}

Peng, H. B., T. G. Ristroph, G. M. Schurmann, G. M. King, J. Yoon, V. Narayanamurti, and J. A. Golovchenko. 2003. Patterned Growth of Single-Walled Carbon Nanotube Arrays from a VaporDeposited Fe Catalyst. Applied Physics Letters 83, no. 20: 4238. doi:10.1063/1.1627935.

\section{Published Version}

doi:10.1063/1.1627935

\section{Permanent link}

http://nrs.harvard.edu/urn-3:HUL.InstRepos:29405821

\section{Terms of Use}

This article was downloaded from Harvard University's DASH repository, and is made available under the terms and conditions applicable to Other Posted Material, as set forth at http:// nrs.harvard.edu/urn-3:HUL.InstRepos:dash.current.terms-of-use\#LAA

\section{Share Your Story}

The Harvard community has made this article openly available.

Please share how this access benefits you. Submit a story.

\section{Accessibility}




\title{
Patterned growth of single-walled carbon nanotube arrays from a vapor-deposited Fe catalyst
}

\author{
H. B. Peng \\ Division of Engineering and Applied Sciences, Harvard University, Cambridge, Massachusetts 02138 \\ T. G. Ristroph, G. M. Schurmann, G. M. King, and J. Yoon ${ }^{\text {a) }}$ \\ Department of Physics, Harvard University, Cambridge, Massachusetts 02138 \\ V. Narayanamurti ${ }^{\text {b) }}$ and J. A. Golovchenko ${ }^{\text {b),c) }}$ \\ Division of Engineering and Applied Sciences, Harvard University, Cambridge, Massachusetts 02138
}

(Received 27 June 2003; accepted 10 September 2003)

\begin{abstract}
Single-walled carbon nanotubes have been grown on a variety of substrates by chemical vapor deposition using low-coverage vacuum-deposited iron as a catalyst. Ordered arrays of suspended nanotubes ranging from submicron to several micron lengths have been obtained on $\mathrm{Si}, \mathrm{SiO}_{2}$, $\mathrm{Al}_{2} \mathrm{O}_{3}$, and $\mathrm{Si}_{3} \mathrm{~N}_{4}$ substrates that were patterned on hundred nanometer length scales with a focused ion beam machine. Electric fields applied during nanotube growth allow the control of growth direction. Nanotube circuits have been constructed directly on contacting metal electrodes of $\mathrm{Pt} / \mathrm{Cr}$ patterned with catalysts. Patterning with solid iron catalyst is compatible with modern semiconductor fabrication strategies and may contribute to the integration of nanotubes in complex device architectures. () 2003 American Institute of Physics. [DOI: 10.1063/1.1627935]
\end{abstract}

Carbon nanotubes have attracted intense attention in recent years due to their interesting physical properties and potential applications. ${ }^{1,2}$ The controlled growth of carbon nanotubes is critical in practical applications and a number of recent reports have addressed this issue. ${ }^{3-9}$ For example, Dai's group ${ }^{8}$ obtained suspended single-walled nanotubes (SWNTs) oriented parallel to the substrate surfaces on specific sites by a methane chemical vapor deposition (CVD) growth method. This method relies on liquid solutions containing catalyst nanoparticles, which are transferred to patterned substrate surfaces by contact printing. There are also reports of multiwalled carbon nanotube growth from vapor deposited solid catalyst films. ${ }^{4,5,9-11}$ However, little work has been done on directing the controlled growth of SWNTs on specific sites using solid catalyst films. ${ }^{12}$ Here, we show that very low coverage of vapor-deposited $\mathrm{Fe}$ serves as a reliable catalyst for the growth of SWNTs. By patterning the Fe catalyst, we obtain ordered arrays of suspended SWNTs on predefined locations using a methane CVD growth method. Furthermore, locally applied, "on chip" electric fields ${ }^{13}$ were utilized to successfully manipulate the growth directions of SWNTs. Finally, device-quality SWNTs were grown directly on catalyzed metal electrodes with good electrical contact.

In our experiments, Fe was deposited by thermal evaporation in a vacuum of $10^{-6}$ Torr. The Fe coverage was typically $5 \times 10^{15}$ atoms $/ \mathrm{cm}^{2}$ (corresponding to a few monolayers) as determined by Rutherford backscattering. Catalyst regions were patterned into arrays of small posts or parallel stripes of different dimensions by using a focused ion beam (FIB) machine (FEI Micrion 9500, $50 \mathrm{kV}$ ). Unless otherwise

\footnotetext{
a) Also at: Department of Physics, Massachusetts Institute of Technology, Cambridge, MA 02139.

${ }^{b)}$ Also at: Department of Physics, Harvard University, Cambridge, MA 02138

c)Electronic mail: golovchenko@physics.harvard.edu
}

specified in the letter, nanotubes were then grown in a quartz tube oven at a temperature of $900{ }^{\circ} \mathrm{C}$ in the flow of methane $(1000 \mathrm{sccm})$ for 4-20 min. ${ }^{8}$ Heating up and cooling down were done in an argon flow. High-resolution scanning electron microscopy (SEM) and transmission electron microscopy (TEM) were used to characterize the carbon nanotubes. For TEM imaging, multiple gaps or holes were ion beam etched all the way through self-supporting $0.5-\mu \mathrm{m}$-thick $\mathrm{Si}_{3} \mathrm{~N}_{4}$ membranes. ${ }^{14}$ The substrate then formed a natural electron microscope grid upon which nanotubes could be grown and studied by TEM directly.

Figures 1(a)-1(d) show the growth behavior of nanotubes on patterned $\mathrm{Si}_{3} \mathrm{~N}_{4}$ membranes as observed with a SEM operated at $1 \mathrm{keV}$. Using such a low energy SEM allows direct observation of suspended nanotubes. The width of the Fe coated $\mathrm{Si}_{3} \mathrm{~N}_{4}$ regions on different patterns ranged from 200 to $500 \mathrm{~nm}$. These regions clearly serve as the initiation and termination sites in the nanotube growth process.

Figure 1(a) shows the nanotubes grown across $500 \mathrm{~nm}$ wide gaps. The growth time was $10 \mathrm{~min}$ in the methane flow. Most crossing nanotubes were grown in directions approximately perpendicular to the long gap direction. As the gap width is increased to $700 \mathrm{~nm}, 1.3$, and $3 \mu \mathrm{m}$ [Figs. 1(b), 1(c), 1(d), respectively], the nanotube density decreases and the tubes that succeed in traversing the gap are more nearly aligned perpendicular to it. A likely explanation is that the Van der Waals' interaction between the thermally vibrating nanotubes $^{13}$ and the substrate successfully returns most nanotubes to the substrate segment they start from, unless their initial growth direction is nearly perpendicular to the gap, or a tube-tube collision results in growth in that direction. Long suspended nanotubes can be easily obtained even for gaps exceeding $5 \mu \mathrm{m}$. Near the edges, two or more tubes usually join together to form a long tube across the gaps. This demonstrates that interactions between the floating 

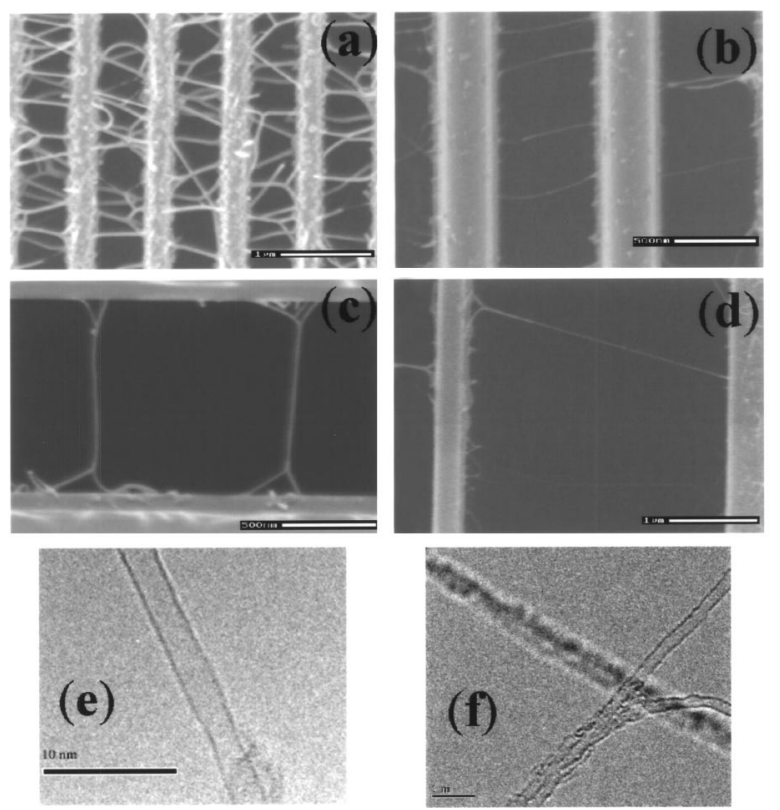

FIG. 1. SEM (a)-(d) and TEM (e), (f) images of nanotubes across parallel gaps etched through free-standing $\mathrm{Si}_{3} \mathrm{~N}_{4}$ membranes. (a) $500 \mathrm{~nm}$ wide gaps with remaining stripes $300 \mathrm{~nm}$ wide. Scale bar: $1 \mu \mathrm{m}$. (b) Gaps $700 \mathrm{~nm}$ wide. Scale bar: $500 \mathrm{~nm}$. (c) Gaps $1.3 \mu \mathrm{m}$ wide. Scale bar: $500 \mathrm{~nm}$. (d) Gaps $3 \mu \mathrm{m}$ wide. Scale bar: $1 \mu \mathrm{m}$. (e) TEM image of a suspended individual SWNT. Scale bar: $10 \mathrm{~nm}$. (f) From bottom left to top right: the split of a nanotube bundle into two individual SWNTs. From top left to bottom right: an out-of-focus image of another nanotube. Scale bar: $5 \mathrm{~nm}$.

nanotubes during the growth process are important in forming nanotube structures.

TEM $(200 \mathrm{kV})$ images were taken of suspended nanotubes grown across gaps on catalyst-coated $\mathrm{Si}_{3} \mathrm{~N}_{4}$ membranes. In Fig. 1(e), the wall structure of an individual SWNT is clearly seen. Figure 1(f) shows the split of a twotube bundle into two individual SWNTs $2 \mathrm{~nm}$ in diameter. Most of the nanotubes observed in our samples, even very long nanotubes, are isolated individual SWNTs, or bundles made of only a few SWNTs. The diameter of most SWNTs ranges from 1 to $4 \mathrm{~nm}$ from TEM studies. It has been suggested that nanometer-sized catalyst particles are required to seed nanotube growth. ${ }^{15-18}$ Gaseous carbon compounds presumably decompose on the surface of catalytic metal droplets, and carbon nanotube growth occurs by diffusion-driven precipitation of carbon from the supersaturated catalyst nanoparticles. For low coverage Fe depositions, nanoscale droplets nucleate at the surface during the high temperature treatment. ${ }^{10,11}$ From atomic force microscopy images taken on $\mathrm{Fe}$ deposited surfaces before and after annealing at $900^{\circ} \mathrm{C}$ with argon flow, we clearly observe the aggregation of nanoparticles (ranging from nanometers to hundreds of nanometers) due to the heating process. Also, at both ends of the nanotubes observed by SEM, the size of nucleation sites is of order or less than the resolution of the SEM $(\sim 10 \mathrm{~nm})$. Therefore, they possibly grow from $10 \mathrm{~nm}$ or smaller Fe particles.

We also studied the growth behavior of nanotubes on different substrates commonly encountered in semiconductor device fabrication, such as $\mathrm{Si}(111), \mathrm{Si}(100), \mathrm{SiO}_{2}$, and $\mathrm{Al}_{2} \mathrm{O}_{3}$. Figure 2(a) shows nanotubes crossing trenches 700 $\mathrm{nm}$ wide on a $\mathrm{Si}$ substrate coated with insulating $\mathrm{SiO}_{2}$ layer for a growth time of $20 \mathrm{~min}$. In Fig. 2(b), suspended nanoDownloaded 09 Dec 2005 to 128.103.60.225. Redistribution subject
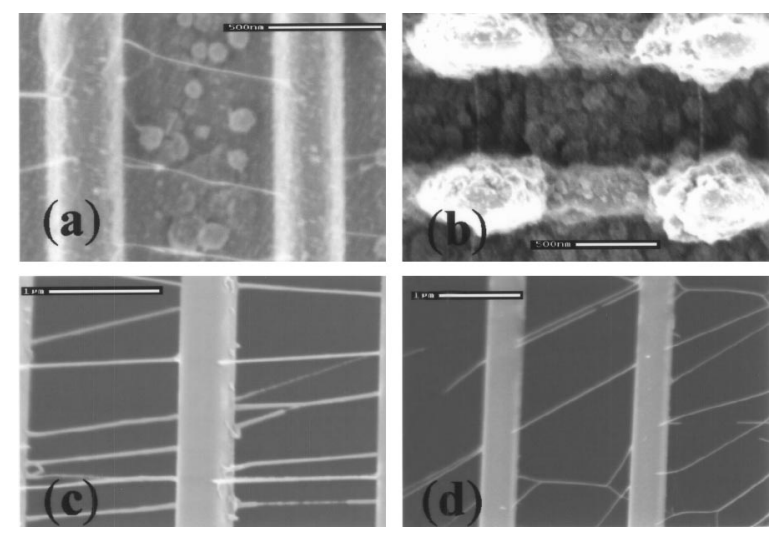

FIG. 2. SEM images of SWNTs connecting stripes or posts patterned on (a) a $\mathrm{SiO}_{2}(5000 \AA) / \mathrm{Si}$ substrate (grains due to etching are seen in the bottom of the trenches. Scale bar: $500 \mathrm{~nm})$ and (b) an $\mathrm{Al}_{2} \mathrm{O}_{3}(1000 \AA) / S i$ substrate (Scale bar: $500 \mathrm{~nm}$ ). (c) SEM images of SWNTs across gaps in $\mathrm{Si}_{3} \mathrm{~N}_{4}$ membranes with 4 min growth time, under applied electric field perpendicular to the gaps $(0.5 \mathrm{~V} / \mu \mathrm{m})$ and (d) at a $45^{\circ}$ angle relative to the gaps $(2.4$ $\mathrm{V} / \mu \mathrm{m})($ Scale bar: $1 \mu \mathrm{m})$.

tubes are connecting arrays of post on $\mathrm{Al}_{2} \mathrm{O}_{3}$ coated Si substrate.

So far, the directional alignment of nanotubes in our experiment is mainly determined by nanotube-substrate and nanotube-nanotube interactions and thermal vibrations, which make most of the nanotubes orient themselves roughly in a direction perpendicular to the gaps or trenches. To get better control in the growth of nanotubes we explored the utility of applying electric fields to align the nanotubes during the growth process. ${ }^{13,19}$ Here we show that locally applied electric fields are very effective in manipulating the growth direction of SWNTs from our Fe catalyzed surfaces. In our experimental setup, two $20 \mu \mathrm{m}$ wide electrodes (Pt 40 $\mathrm{nm} / \mathrm{Ti} 50 \mathrm{~nm}$ ) spaced $10 \mu \mathrm{m}$ apart end on, were patterned by optical lithography on self supported insulating $\mathrm{Si}_{3} \mathrm{~N}_{4}$ membranes. The Fe catalyst was deposited in the space between the electrodes, and then that space was patterned into parallel gaps with the FIB. During the CVD growth process, a bias voltage was applied between the electrodes to generate an electric field in the gap areas. Figure 2(c) shows the result for a sample under a bias voltage of $5 \mathrm{~V}$ and 4 min growth time. The electric field direction was perpendicular to the gaps. Compared with the results without electric fields during growth, the nanotubes look straighter, and are more aligned with the applied field. It has been previously suggested that the interaction between the external electric field and the induced dipole moment of a SWNT is the driving force for the alignment. ${ }^{13}$ To further demonstrate the effect of electric fields, we also prepared samples with gaps at a $45^{\circ}$ angle relative to the applied field direction. As illustrated in Fig. 2(d), most of the SWNTs are now aligned to the new electric field direction, although there are still some SWNTs in the perpendicular direction, which is due to the competing driving forces as described previously (Van der Waals interactions and thermal vibrations). It should be clear from these results that orientational growth can be programmed to obtain structures that contain crossed nanotubes, which could be very important as device structures.

Finally, we show that the growth strategy can be applied to obtain SWNTs directly on metal electrodes with good to AIP license or copyright, see http://apl.aip.org/apl/copyright.jsp 

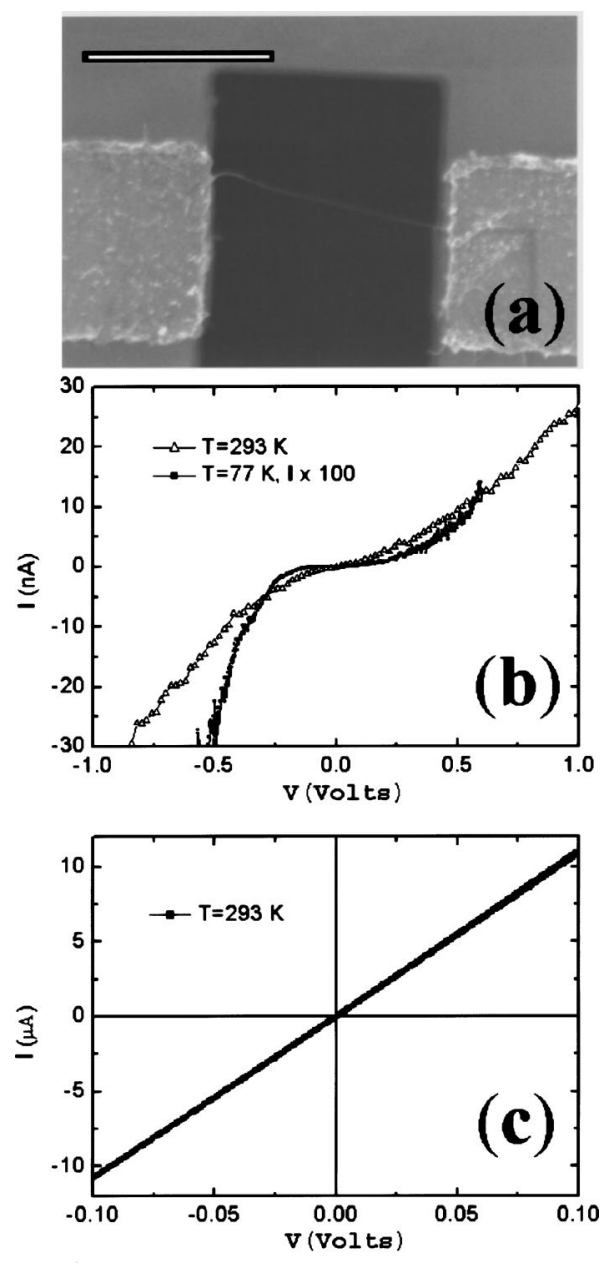

FIG. 3. (a) A suspended SWNT connecting $2 \mu \mathrm{m}$ wide metal electrodes (Pt $50 \mathrm{~nm} / \mathrm{Cr} 50 \mathrm{~nm}$ ), across a gap etched all the way through the $\mathrm{Si}_{3} \mathrm{~N}_{4}$ membrane. Scale bar: $2 \mu \mathrm{m}$. (b) $I$ vs $V$ curves for a sample with suspended semiconducting SWNTs at temperatures of $T=293 \mathrm{~K}$ (triangles) and $T$ $=77 \mathrm{~K}$ (squares). The current $(I)$ values for $T=77 \mathrm{~K}$ are multiplied by a factor of 100 . (c) $I-V$ curve for a sample with metallic SWNTs at room temperature.

electrical contact. Two $2 \mu \mathrm{m}$ wide electrodes $(\mathrm{Pt} 50 \mathrm{~nm} / \mathrm{Cr}$ $50 \mathrm{~nm}$ ) with Fe catalyst on top, spaced apart end on with a $\sim 2 \mu \mathrm{m}$ gap between them, were lithographically patterned in the center of $\mathrm{Si}_{3} \mathrm{~N}_{4}$ membrane. A FIB was used to mill the gaps between the electrodes all the way through the $\mathrm{Si}_{3} \mathrm{~N}_{4}$ membranes. CVD nanotube growth was carried out from 2 to $5 \mathrm{~min}$ in a methane flow of $200 \mathrm{sccm}$ at $900{ }^{\circ} \mathrm{C}$, which usually yields only one or a few suspended SWNTs across the gaps between electrodes. Figure 3(a) shows a typical sample with a SWNT bridging an electrode gap. With this growth condition, amorphous carbon deposition on the substrate makes no contribution to the measured nanotube electrical properties. All the electrical measurement were made on the as-grown samples, without any postgrowth contacting process. Figure 3(b) shows the $I-V$ curves for a semiconducting SWNT. At room temperature, the low-bias differential resistance is $\sim 100 \mathrm{M} \Omega$, and band gap-related nonlinearity is already visible. An asymmetry appears which is most likely due to contact difference at the two ends of the tube. When the temperature is reduced to $77 \mathrm{~K}$, a gap is clearly observed in the $I-V$ curve. Figure 3(c) shows the room tem- perature $I-V$ curve of a sample with metallic SWNTs. The linear resistance for this metallic sample is $\sim 10 \mathrm{k} \Omega$.

In summary, ordered SWNT arrays were grown by thermal CVD from patterned vapor deposited Fe catalysts on different substrates. External electric fields were shown to be effective in manipulating the orientation of SWNTs during the growth process despite competing tendencies. SWNT circuits with electrical contacts were constructed using the method, which may be useful in practical electronic device fabrication strategies. The controlled growth, and incorporation, of nanotubes in different geometries is important for applications in electronic, mechanical, and chemical devices. ${ }^{2}$ For example, nanotubes across gaps in the freestanding membranes provide a good device geometry for chemical sensors. Crossed nanotubes bridged by appropriate molecules may provide true single molecule negative differential resistance device capabilities. ${ }^{14}$ We note that our growth strategy is highly compatible with, and adaptable to, standard semiconductor lithography processing techniques. It may therefore be important for the adoption of carbon nanotubes in future large scale practical applications which will most likely require integration with silicon based technology.

The authors thank Dr. Warren MoberlyChan for the help with TEM and Dr. JuanCarlos Cheang for the help with Rutherford backscattering spectroscopy. This work is supported by the DARPA/AFOSR and the NSF.

${ }^{1}$ S. Iijima, Nature (London) 354, 56 (1991).

${ }^{2}$ Carbon Nanotubes: Synthesis, Structure, Properties, and Applications, edited by M. S. Dresselhaus, G. Dresselhaus, and P. Avouris (Springer, Berlin, 2001).

${ }^{3}$ W. Z. Li, S. S. Xie, L. X. Qian, B. H. Chang, B. S. Zou, W. Y. Zhuo, R. A. Zhao, and G. Wang, Science 274, 1701 (1996).

${ }^{4}$ Z. F. Ren, Z. P. Huang, J. W. Xu, J. H. Wang, P. Bush, M. P. Siegal, and P. N. Provencio, Science 282, 1105 (1998).

${ }^{5}$ S. Fan, M. G. Chapline, N. R. Franklin, T. W. Tombler, A. M. Cassell, and H. Dai, Science 283, 512 (1999).

${ }^{6}$ J. Kong, H. T. Soh, A. M. Cassell, C. F. Quate, and H. J. Dai, Nature (London) 395, 878 (1998).

${ }^{7}$ J. Li, C. Papadopoulos, J. M. Xu, and M. Moskovits, Appl. Phys. Lett. 75, 367 (1999).

${ }^{8}$ A. M. Cassell, N. R. Franklin, T. W. Tombler, E. M. Chan, J. Han, and H. Dai, J. Am. Chem. Soc. 121, 7975 (1999). After finishing this manuscript, we learned of similar results about growth of nanotubes on electrodes using catalysts from solutions. N. R. Franklin, Q. Wang, T. W. Tombler, A. Javey, M. Shim, and H. Dai, Appl. Phys. Lett. 81, 913 (2002).

${ }^{9}$ Z. F. Ren, Z. P. Huang, D. Z. Wang, J. G. Wen, J. W. Xu, J. H. Wang, L. E. Calvet, J. Chen, J. F. Klemic, and M. A. Reed, Appl. Phys. Lett. 75, 1086 (1999).

${ }^{10}$ Y. Y. Wei, G. Eres, V. I. Merkulov, and D. H. Lowndes, Appl. Phys. Lett. 78, 1394 (2001)

${ }^{11}$ J. I. Sohn, C. Choi, S. Lee, and T. Seong, Appl. Phys. Lett. 78, 3130 (2001).

${ }^{12}$ Note: An early version of this letter was finished in March 2002. Recently, there was a work on using nickel-iron thin film catalysts to grow small diameter nanotubes with ethylene gas. P. M. Campbell, E. S. Snow, and J. P. Novak, Appl. Phys. Lett. 81, 4586 (2002).

${ }^{13}$ Y. Zhang, A. Chang, J. Cao, Q. Wang, W. Kim, Y. Li, N. Morris, E. Yenilmez, J. Kong, and H. Dai, Appl. Phys. Lett. 79, 3155 (2001).

${ }^{14}$ J. Chen, M. A. Reed, A. M. Rawlett, and J. M. Tour, Science 286, 1550 (1999).

${ }^{15}$ N. M. Rodriguez, J. Mater. Res. 80, 3233 (1993).

${ }^{16}$ H. Kanzow and A. Ding, Phys. Rev. B 60, 11180 (1999).

${ }^{17}$ R. T. K. Baker, Carbon 27, 315 (1989).

${ }^{18}$ Y. Li, W. Kim, Y. Zhuang, M. Rolandi, D. Wang, and H. Dai, J. Phys. Chem. B 105, 11424 (2001).

${ }^{19}$ Y. Avigal and R. Kalish, Appl. Phys. Lett. 78, 2291 (2001). 